\title{
Numerical simulations of bedrock erosion around the bridge
}

\author{
C.T. Liao \\ Prevention \& Water Environment Research Center, National Chiao Tung University, Taiwan \\ K.C. Yeh, K.W. Li, R.K. Jhong \& K.W. Wu \\ Department of Civil Engineering, National Chiao Tung University, Taiwan
}

\begin{abstract}
There are bedrock erosion problems in western Taiwan. A bridge or an instream structure in the river often affects the sediment transport, and then leads to severe bed change and local scour problems. Bedrock channels lack a continuous cover of alluvial sediments over the long term. When the bed armor layer flushed away, it makes the bedrock exposed, and then increases the channel incision. There are significant bedrock erosion problems in the nearby area of Chungcheng Bridge in Touchien River, Taiwan. However, hydraulic models of past few decades often aimed at the sediment transport of alluvial channel. The numerical simulation of bedrock erosion is an important issue for the planning of stable countermeasures. In this study, a two-dimensional mobile-bed model, called CCHE2D is adopted to simulate the bedrock erosion process in the nearby area of Chungcheng Bridge. A stream power with flow shear stress method of bedrock incision rate formula is established in the model. The results show that the model has the capability of simulating flow field and morphological changes in study reach.
\end{abstract}

\section{INTRODUCTION}

Steep slope and severe bed change during floods are the common characteristics in Taiwan's rivers. It often causes the bed armor layer flushed away when upstream sediment supply is insufficient. It makes the soft bedrock exposed, increase the channel incision, and endanger the safety of instream structures or protection works along the river.

Most mobile-bed models of past few decades aimed at the sediment transport of alluvial channel. Lai et al. (2011) proposed a two-dimensional mobile-bed model that considered both hydraulic and abrasive scour of bedrock erosion mechanisms. The model was applied to simulate the bed evolution downstream of Chi-Chi weir in Choushui River, Taiwan. Yeh et al. (2008) also presented a bedrock model which modified the abrasion model of Sklar and Dietrich (2004) to simulate the same case. Liao et al. (2014) developed a 2-D mobile-bed model with bedrock erosion mechanism for natural rivers. The stream power with flow shear stress method of bedrock incision rate formula is proposed and established in the model.

In this study, a two-dimensional mobile-bed model, called CCHE2D, is adopted to simulate the channel migration in the nearby area of Chungcheng Bridge in Touchien River, Taiwan. The bedrock erosion mechanism proposed by Liao et al. (2014) is considered in the model. Data associated with suspended sediment concentration, bed material grain sizes, erodibility index of bedrock and digital surface model are collected and established. These basic data are used to calibrate the numerical model.

\section{NUMERICAL MODEL}

\subsection{Flow module}

Governing equations of the flow are twodimensional depth integrated Reynolds equations in a Cartesian coordinate system are:

$$
\begin{aligned}
& \frac{\partial u}{\partial t}+u \frac{\partial u}{\partial x}+v \frac{\partial u}{\partial y}=-g \frac{\partial \eta}{\partial x}+\frac{1}{h}\left(\frac{\partial h \tau_{x x}}{\partial x}+\frac{\partial h \tau_{x y}}{\partial y}\right)-\frac{\tau_{b x}}{\rho h}+f_{C o r} v \\
& \frac{\partial v}{\partial t}+u \frac{\partial v}{\partial x}+v \frac{\partial v}{\partial y}=-g \frac{\partial \eta}{\partial y}+\frac{1}{h}\left(\frac{\partial h \tau_{y x}}{\partial x}+\frac{\partial h \tau_{y y}}{\partial y}\right)-\frac{\tau_{b y}}{\rho h}-f_{C o r} u
\end{aligned}
$$

where $u$ and $v$ are depth-integrated velocity components in $x$ and $y$ directions, respectively; $t$ is the time; $g$ is the gravitational acceleration; $\eta$ is the water surface elevation; $\rho$ is the density of water; $h$ is the local water depth; $f_{C o r}$ is the Coriolis parameter; $\tau_{x x}, \tau_{x y}$, $\tau_{y x}$, and $\tau_{y y}$ are depth integrated Reynolds stresses; and $\tau_{b x}$ and $\tau_{b y}$ are shear stresses on the bed and flow interface. The shear stress terms at the water sur- 
face are dropped since wind shear driven effect is not considered in this version of the model.

Free surface elevation for the flow is calculated by the depth-integrated continuity equation:

$\frac{\partial h}{\partial t}+\frac{\partial u h}{\partial x}+\frac{\partial v h}{\partial y}=0$

Two methods for calculating eddy viscosity are available in the current model, including the depth integrated parabolic eddy viscosity formula and depth integrated mixing length eddy viscosity model. (Jia, et al. 1999, 2002, 2008)

\subsection{Sediment transport module}

The sediment transport model consists of suspended sediment transport and bed load transport simulation models for non-uniform sediment. The model is also designed to simulate channel bed with large slopes and curved channel secondary flow effects. The depth-integrated convection diffusion for the suspended sediment is solved.

$\frac{\partial C}{\partial t}+u \frac{\partial C}{\partial x}+v \frac{\partial C}{\partial y}-\frac{\partial}{\partial x}\left[\beta v_{t} \frac{\partial C}{\partial x}\right]-\frac{\partial}{\partial y}\left[\beta v_{t} \frac{\partial C}{\partial y}\right]=S+S_{r}$

where $C$ is the depth-integrated sediment concentration, and $\beta$ is the coefficient to convert the turbulence eddy viscosity to eddy diffusivity for sediment. $S$ is a source term representing the balance of sediment pick up and deposition near the surface of the bed. More detail of this term can be found in the technical report of the sediment model (Wu, 2001).

In the processes of vertical integration, one has to either assume the water is shallow and the vertical variation of the flow is negligible or keep the dispersion terms to preserve the effect of vertical sediment profiles on bed form change. In the second case, the source term $S_{r}$ would not be zero, but representing the dispersion terms. Computing the dispersion term is complicated and requires the knowledge of the vertical velocity and suspended sediment profiles in $\mathrm{x}$ and $\mathrm{y}$ directions. Several assumptions are necessary to make it possible to compute this term:

- Assume the vertical velocity in longitudinal and transverse direction is of power law (or logarithms) and linear distribution, the suspended sediment in vertical direction is of Rouse;

- Compute a local orthogonal curvilinear grid based on the flow direction and flow curvature;

- The dispersion terms can be computed on this grid;

- The computed dispersion terms will be transformed back into $x-y$ coordinate;

- Compute $S_{r}$.

\subsection{Bedrock module}

An empirical relation between rate of energy dissipation of flowing water and erodibility of the material can represent the hydraulic erodibility of bedrock river (Annandale, 1995). Incipient motion occurs when the erosive capacity of flow just exceeds the ability of bed material to resist removal, and signals the beginning of the scour process. Figure 1 shows the erosion threshold for rock and other complex earth material developed by Annandale (2006). The rate of energy dissipation is considered to represent the relative magnitude of erosive power of flowing water. The erosion threshold equations can be expressed as:

$$
\begin{array}{lll}
P_{c}=0.48 K_{h}^{0.44} & \text { for } & K_{h} \leq 0.1 \\
P_{c}=K_{h}^{0.75} & \text { for } & K_{h}>0.1
\end{array}
$$

where $P_{c}$ is critical stream power $\left(\mathrm{kw} / \mathrm{m}^{2}\right) ; K_{h}$ is erodibility index of bed material. The erodibility index, $K_{h}$, can be defined as:

$K_{h}=M_{s} \cdot K_{b} \cdot K_{d} \cdot J_{s}$

where $M_{S}$ is mass strength number; $K_{b}=$ block size number; $K_{d}$ is discontinuity bond shear strength number; $J_{s}$ is relative ground structure number. Erodibility index was originally developed by Kirsten (1982) to characterize the excavatability of earth materials. Annandale (2006) found that this index provides a good indicator of the relative ability of earth materials to resist the erosive capability of water. The erosion threshold method was based on an analysis of 137 field data of spillway performance collected by U.S. Department of Agriculture, observed at Bartlett Dam, Salt River Project, four South African dams, etc.

Generally, erosion rate for bedrock is a relation between flow velocity and rock properties. Erodibility index of bed material quantitatively represents the rock properties. Referring to Annandale's (2006) concept, Huang et al. (2013) proposed an erosion rate formula according to the field observations from 1998 to 2009 in Taan River, Taiwan. The chronological longitudinal cross-sections along the main channel were analyzed in detail. The measured incision depth in the uplifted reach of Taan River from 2004 to 2005 is used for the regression of the empirical formula. The stream power, flow velocity, water depth and shear stress are calculated by hydraulic model. The optimization by the nonlinear least-squares method is conducted to obtain the coefficients of the empirical formula. Based on the theorem mentioned above, the stream power type of bedrock erosion rate formula can be expressed as:

$E=K_{s} U\left(\frac{P}{P_{c m}}-1\right)^{0.2}$

where $E$ is erosion rate of bedrock river bed $(\mathrm{m} / \mathrm{s})$; $K_{s}$ is non-dimensional coefficient; $U$ is depthaveraged velocity of flow $(\mathrm{m} / \mathrm{s}) ; P$ is stream power of flow $\left(\mathrm{kw} / \mathrm{m}^{2}\right), P=\tau U, \tau$ is shear stress $\left(\mathrm{N} / \mathrm{m}^{2}\right) ; P_{c m}$ 
is critical stream power $\left(\mathrm{kw} / \mathrm{m}^{2}\right)$, which can be described as:

$$
P_{c m}=K_{h}^{0.1}
$$

Equation (8) and Equation (9) are the first relation between rate of energy dissipation of flowing water and erodibility index of the bedrock material in Taiwan's River. Liao et al. (2014) applied this bedrock module in a 2-D mobile-bed model to simulate the bedrock incision process in the natural river.

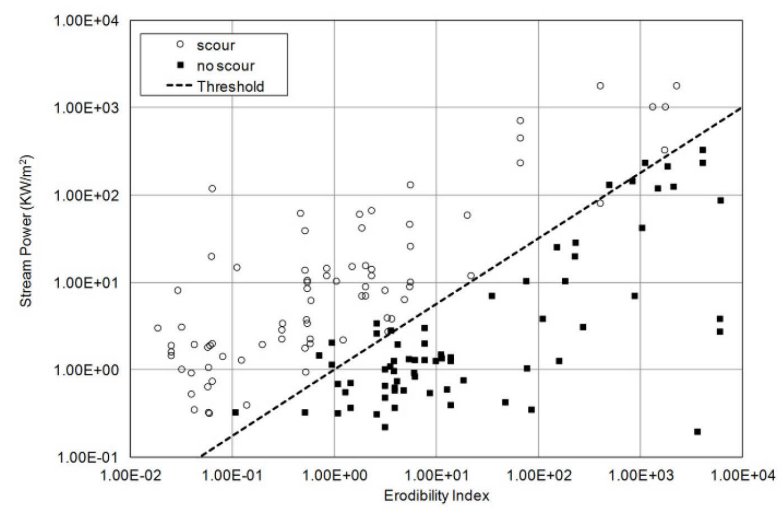

Figure 1. Erosion threshold for rock and other complex earth material (redrawn from Annandale, 2006).

\section{FIELD CASE STUDY}

\subsection{Geological data}

A rapidly varied channel, Touchien River, Taiwan, is chosen as the study site, which is $63 \mathrm{~km}$ in length. Figure 2 shows an aerial photo of the study reach, it is about $4 \mathrm{~km}$ long from upstream Highway Bridge to downstream Lungen Weir. There is an instream structure called Chungcheng Bridge built on the study reach since 1981. According to the measured cross-sections and digital surface models in the past years, it shows there are significant erosion trends in the downstream riverbed of Chungcheng Bridge. The dredging in early stage is the major reason of channel erosion. For the structural safety of Chungcheng Bridge, the protection works are built and modified year by year.

In year 2013, the $9^{\text {th }}$ pier of Chungcheng Bridge was destroyed after the typhoon Soulik, and a new flow path was formed along the right bank side of main channel. There are serious bedrock bank erosion and local scour around this area (shown as Figure 3 and Figure 4). It deeply affects the safety of Chungcheng Bridge due to this channel migration.

Figure 5 shows the historical measured thalwegs in the study reach from Highway Bridge to Lungen Weir. It shows the river is almost stable near the Chungcheng Bridge in year 1985. After the protection works are built on the downstream area of Chungcheng Bridge (since year 1986), the channel has the erosion trends. The maximum erosion depth in main channel is over 15 meters in year 2012. In year 2013, the Chungcheng Bridge was destroyed after the typhoon Soulik, and a new flow path was formed after this destruction. It shows that there is knickpoint migration in upstream. Affected by the new flow path, the downstream riverbed has a few deposition trends in recent years.

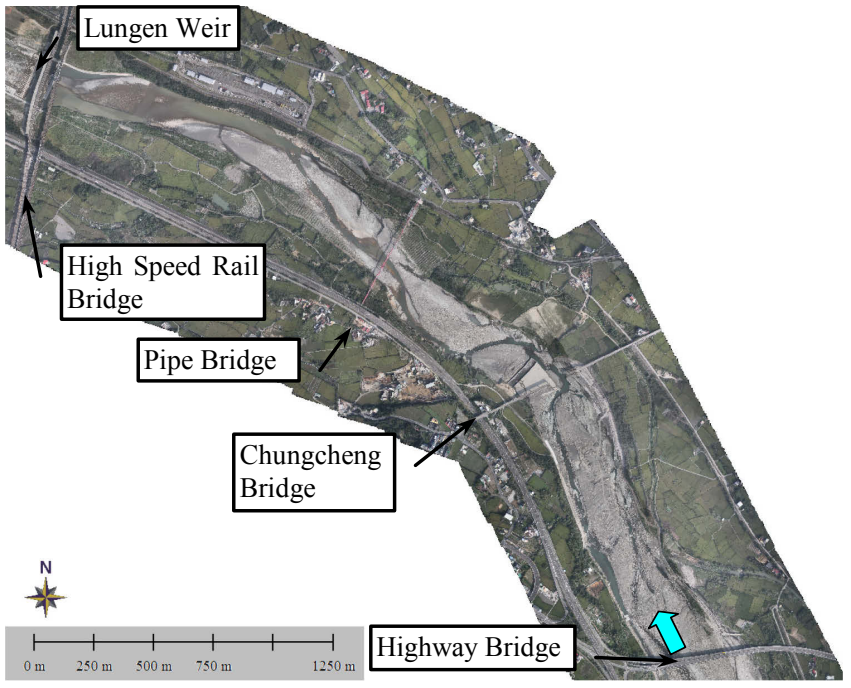

Figure 2. Aerial photo of study reach, Touchien River, Taiwan.

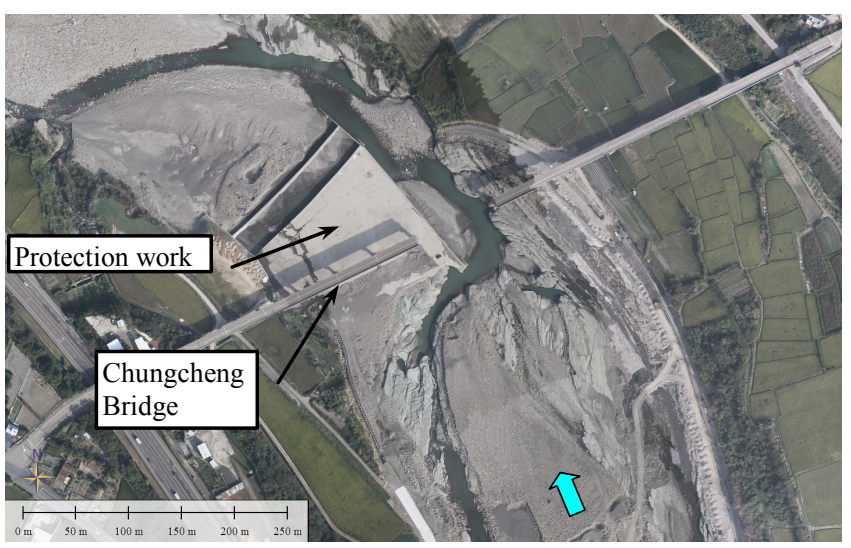

Figure 3. Aerial photo of Chungcheng Bridge.

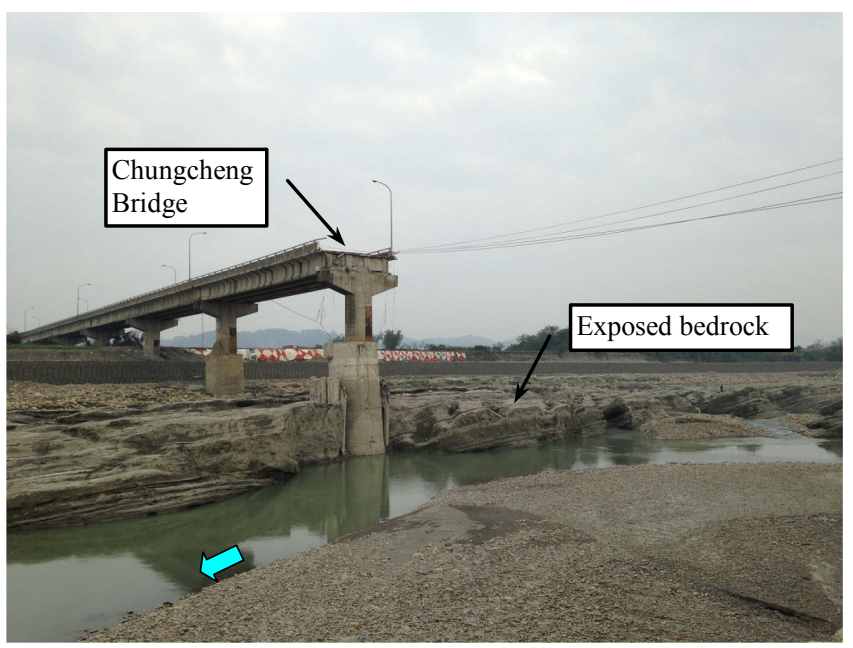

Figure 4. The Chungcheng Bridge was destroyed after the typhoon Soulik in year 2013 . 


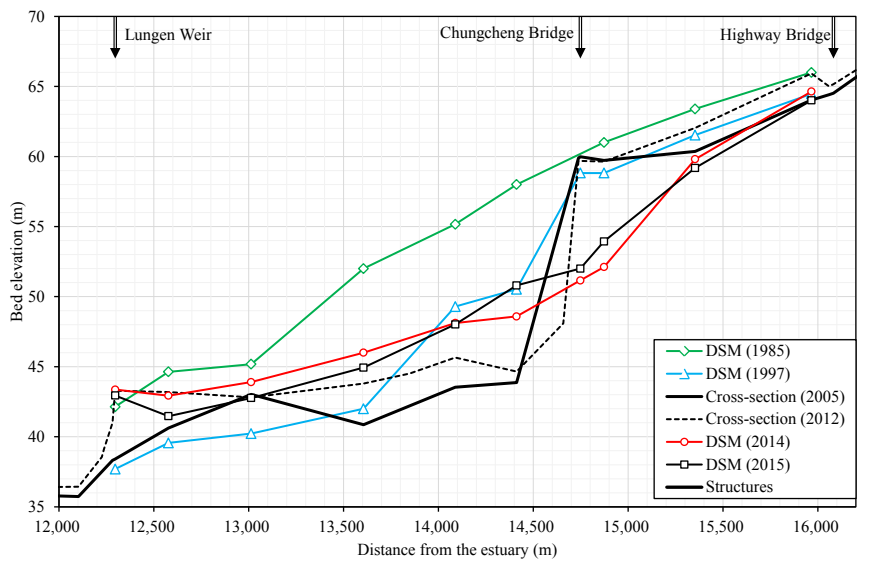

Figure 5. The historical measured thalwegs in the study reach.

\subsection{Hydrological data}

In Touchien River watershed, the average annual precipitation is about $2,240 \mathrm{~mm}$ and $80 \%$ of rainfall occurs in the summer. According to the management and planning report of Tiuchien River, the 100-year return period discharge, $\mathrm{Q}_{100}$, at Chungcheng Bridge is $8,190 \mathrm{~m}^{3} / \mathrm{s}$, and the $\mathrm{Q}_{2}, \mathrm{Q}_{5}$ and $\mathrm{Q}_{10}$ is $2,560 \mathrm{~m}^{3} / \mathrm{s}$, $4,130 \mathrm{~m}^{3} / \mathrm{s}$, and $5,150 \mathrm{~m}^{3} / \mathrm{s}$, respectively. Table 1 shows the historical measured peak discharges during the typhoon or heavy rain in the study reach. It can be seen that the peak discharge of typhoon Soulik is $8,560 \mathrm{~m}^{3} / \mathrm{s}$, which is the most significant flood in the period from year 1991 to 2015 .

\section{NUMERICAL SIMULATIONS}

\subsection{Initial and boundary conditions}

In this study, a 2-D mobile-bed model, called CCHE2D, was adopted to simulate the flow field and bed change in the nearby area of Chungcheng Bridge. The computational domain is from Highway Bridge to Lungen Weir. The DSM data obtained in October, 2014 is used as the initial bed condition, and the data of September, 2015 is used for the calibration by considering the significant flood events occurred in year 2015 .

According to the mean particle size of bed material in study reach, five sediment size classes $(0.03$ $\mathrm{mm}, 22.98 \mathrm{~mm}, 69.56 \mathrm{~mm}, 83.85 \mathrm{~mm}$, and 120.2 $\mathrm{mm}$ ) are used to specify the initial bed compositions in the model. Wu et al. (2000)'s sediment transport formula is adopted in the model. The main parameters in the model for bed evolution simulation are as follows: the adaptation length for bed load is 1,200 $\mathrm{m}$, Armanini and di Silvio (1988)'s method is chosen as the adaptation coefficient for suspended load, and the mixing layer thickness for bed material sorting is $0.3 \mathrm{~m}$. The stream power threshold is used to calculate the bedrock erosion. The bedrock erodibility index surveyed in the field is from 24 to 126 . The depth of armor layer is about 1.0 meters. Figure 6 shows the distribution of bed erodibility in computational domain. Referring the management and planning report of Touchien River, the Manning's coefficient is about 0.038 .

Table 1. The historical measured peak discharges during the typhoon or heavy rain in the study reach.

\begin{tabular}{ccc}
\hline $\begin{array}{c}\text { Typhoon or } \\
\text { Heavy rain }\end{array}$ & $\begin{array}{c}\text { Peak discharge } \\
\left(\mathrm{m}^{3} / \mathrm{s}\right)\end{array}$ & Time \\
\hline Rainstorm 0624 & 542 & $1991 / 06 / 24$ \\
Polly & 2,370 & $1992 / 08 / 30$ \\
Doug & 2,090 & $1994 / 08 / 08$ \\
Fred & 1,060 & $1994 / 08 / 21$ \\
Seth & 1,040 & $1994 / 10 / 10$ \\
Herb & 1,010 & $1996 / 07 / 31$ \\
Prapiroon & 658 & $2000 / 08 / 29$ \\
Nari & 692 & $2001 / 09 / 18$ \\
Rammasun & 860 & $2002 / 07 / 04$ \\
Rananim & 608 & $2004 / 08 / 12$ \\
Aere & 4,410 & $2004 / 08 / 25$ \\
Haima & 878 & $2004 / 09 / 12$ \\
Haitang & 625 & $2005 / 07 / 18$ \\
Matsa & 4,696 & $2005 / 08 / 05$ \\
Talim & 3,684 & $2005 / 09 / 01$ \\
Rainstorm 0410 & 1,060 & $2006 / 04 / 10$ \\
Rainstorm 0610 & 1,105 & $2006 / 06 / 10$ \\
Rainstorm 0607 & 612 & $2007 / 06 / 07$ \\
Wipha & 2,655 & $2007 / 09 / 18$ \\
Krosa & 3,613 & $2007 / 10 / 06$ \\
Sinlaku & 1,436 & $2008 / 09 / 14$ \\
Jangmi & 695 & $2008 / 09 / 28$ \\
Morakot & 1,062 & $2009 / 08 / 07$ \\
Meari & 1,510 & $2010 / 06 / 25$ \\
Rainstorm 0714 & 2,605 & $2011 / 07 / 14$ \\
Rainstorm 0612 & 816 & $2012 / 06 / 12$ \\
Saola & 2,285 & $2012 / 08 / 02$ \\
Soulik & 8,560 & $2013 / 07 / 13$ \\
Trami & 1,432 & $2013 / 08 / 21$ \\
Fitow & 530 & $2013 / 10 / 06$ \\
Soudelor & 1,220 & $2015 / 08 / 08$ \\
\hline & &
\end{tabular}

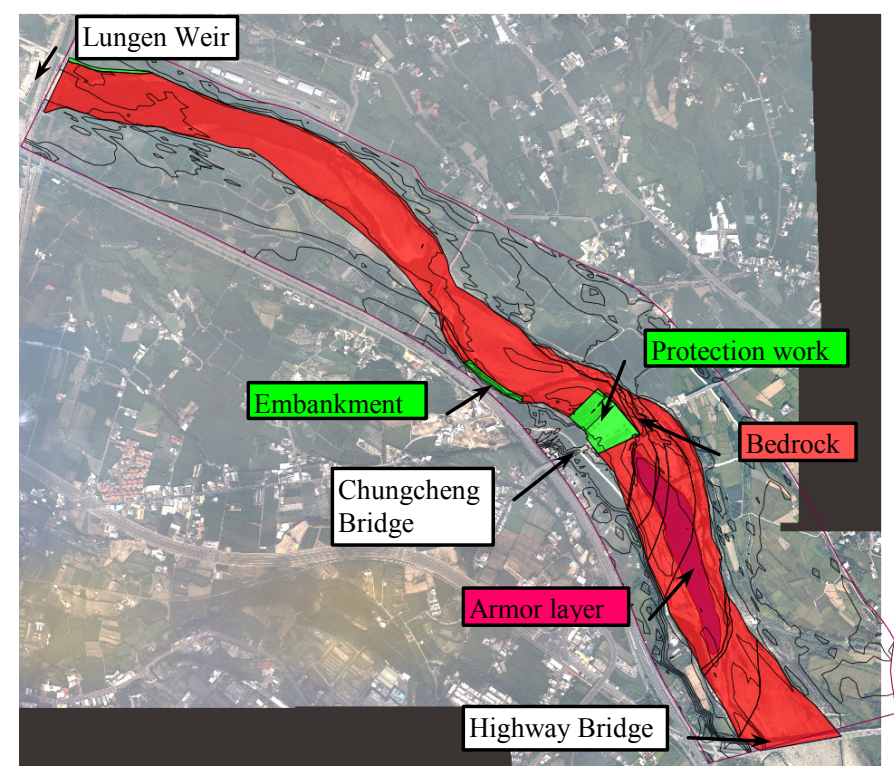

Figure 6. The distribution of bed erodibility in computational domain. 
Figure 7 shows the inflow discharge hydrograph for the model calibration. The rating curve obtained in Chungcheng Bridge is used to calculate the inflow suspended sediment concentration for model calibration. The downstream boundary condition is the water stage hydrograph at Lungen Weir that estimated by 1-D hydrodynamic model. The flow field and velocity magnitude around the Chungcheng Bridge are simulated by considering the different return period floods.

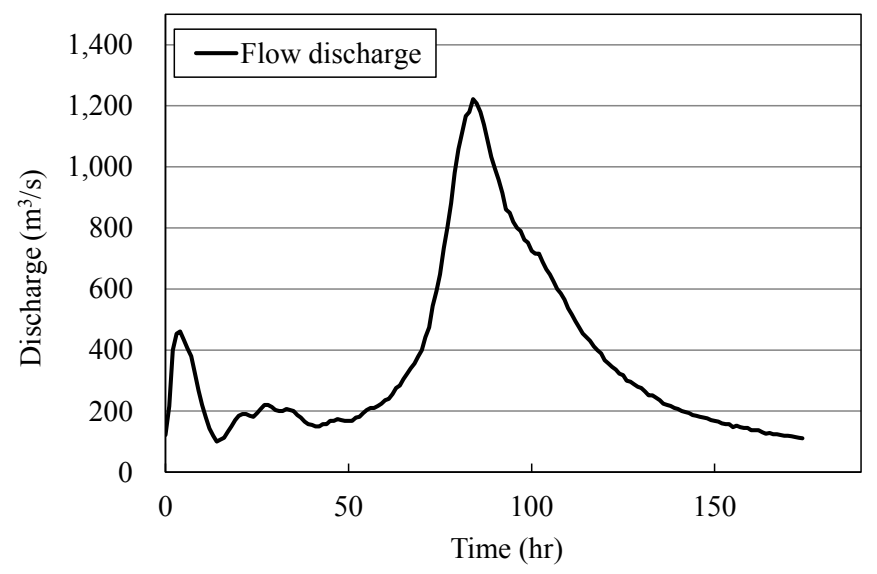

Figure 7. Inflow discharge hydrograph at Highway Bridge during the flood in year 2015.

\subsection{Simulated results and discussions}

\subsubsection{Hydrodynamics}

Figure 8 shows the simulated velocity distribution from Highway Bridge to Lungen Bridge when the inflow discharge is $575 \mathrm{~m}^{3} / \mathrm{s}$. There are two flow paths in the upstream reach. The maximum velocity magnitude is about $5 \mathrm{~m} / \mathrm{s}$ where located on the right bank side of the protection work. Figure 9 and Figure 10 show the simulated flow field around the Chungcheng Bridge when the inflow discharge is $575 \mathrm{~m}^{3} / \mathrm{s}$ and $1,500 \mathrm{~m}^{3} / \mathrm{s}$. In lower discharge, the protection work leads the flow shifting to the right bank and forms a deep main channel. When the inflow discharge is about $1,500 \mathrm{~m}^{3} / \mathrm{s}$, the water will overflow the protection work, and then converge in the downstream reach.

The simulated velocity distribution of different return period floods are shown in Figure 11 and Figure 12. According to the historical peak discharges in Touchien River, the 2-year flood is a common event that causes the channel erosion. The maximum velocity magnitude is occurred near the downstream right flow path of protection work. It may cause the bank erosion and affect the safety of Chungcheng Bridge pier. It is noted that the velocity magnitude increases with the increasing of inflow discharge. When the inflow discharge is $8,190 \mathrm{~m}^{3} / \mathrm{s}$, the maximum velocity magnitude is about $7 \mathrm{~m} / \mathrm{s}$, and the water overflows both the protection work and deep channel at the cross-section of Chungcheng Bridge.

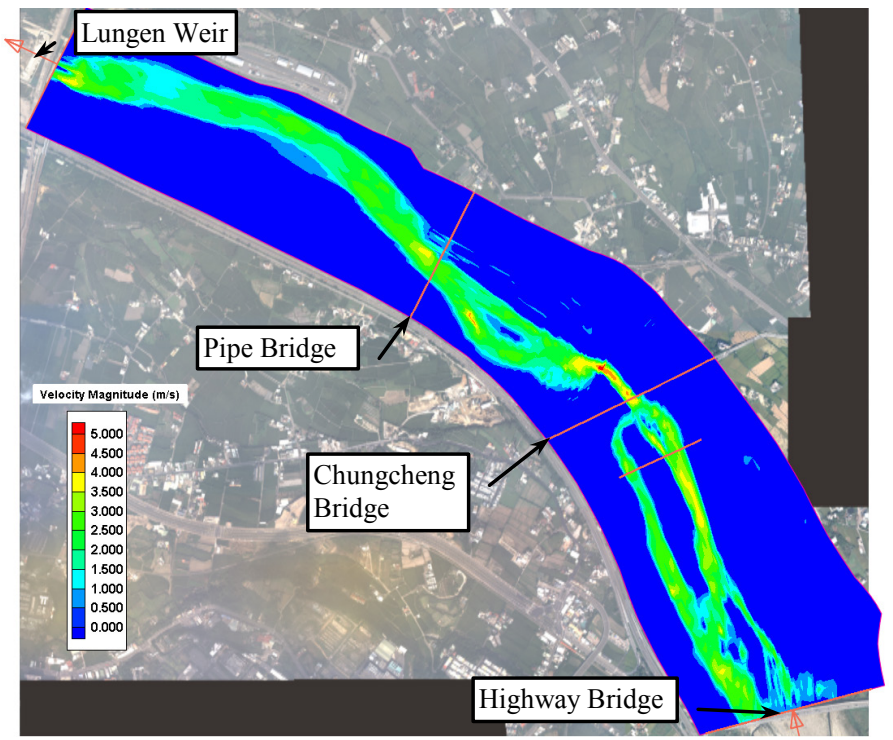

Figure 8 . Simulated velocity distribution in study reach when the inflow discharge is $575 \mathrm{~m}^{3} / \mathrm{s}$.

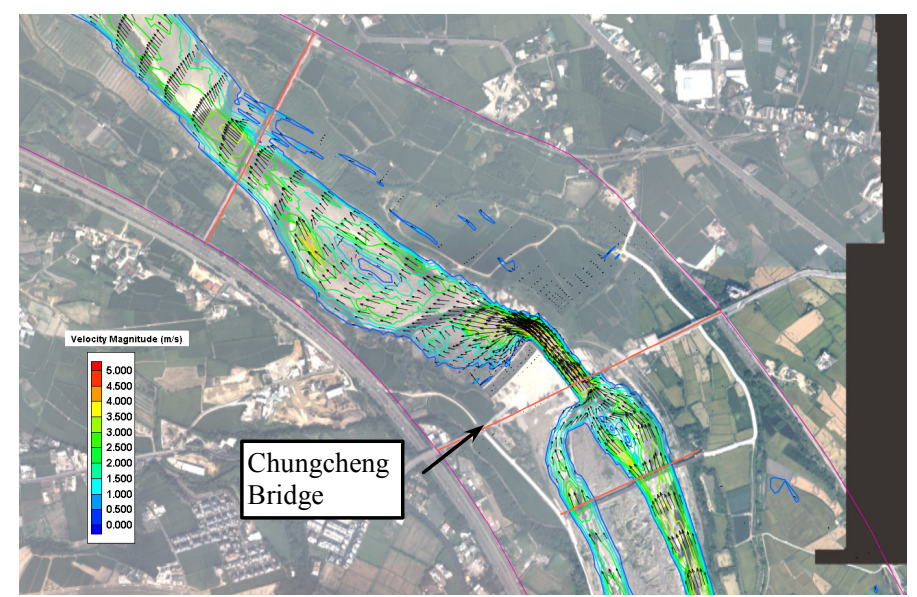

Figure 9. Simulated flow field around Chungcheng Bridge when the inflow discharge is $575 \mathrm{~m}^{3} / \mathrm{s}$.

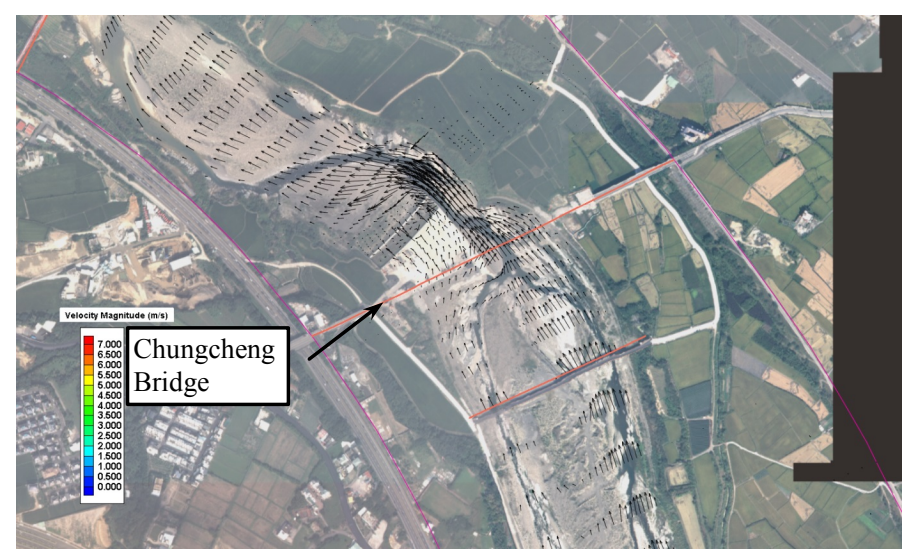

Figure 10. Simulated flow field around Chungcheng Bridge when the inflow discharge is $1,500 \mathrm{~m}^{3} / \mathrm{s}$. 


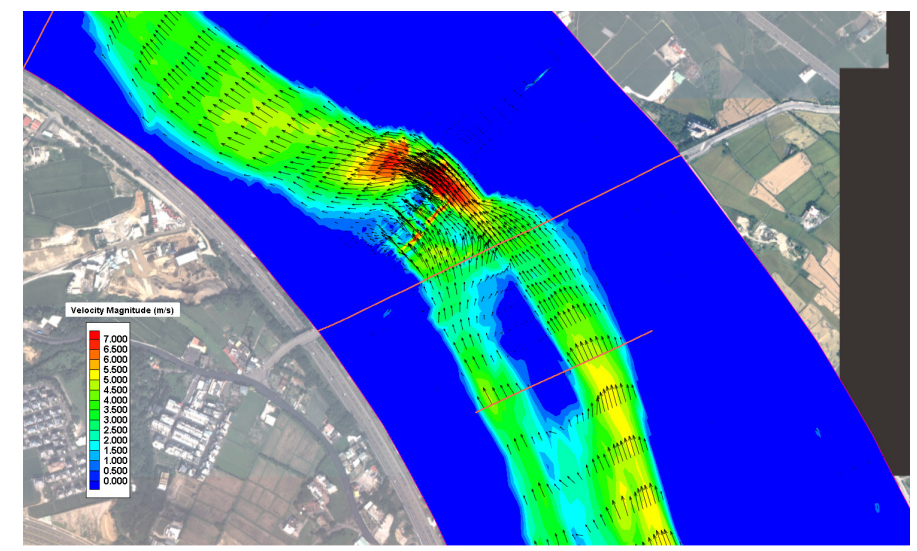

Figure 11. Simulated velocity distribution around Chungcheng Bridge when the inflow discharge is $2,560 \mathrm{~m}^{3} / \mathrm{s}\left(\mathrm{Q}_{2}\right)$.

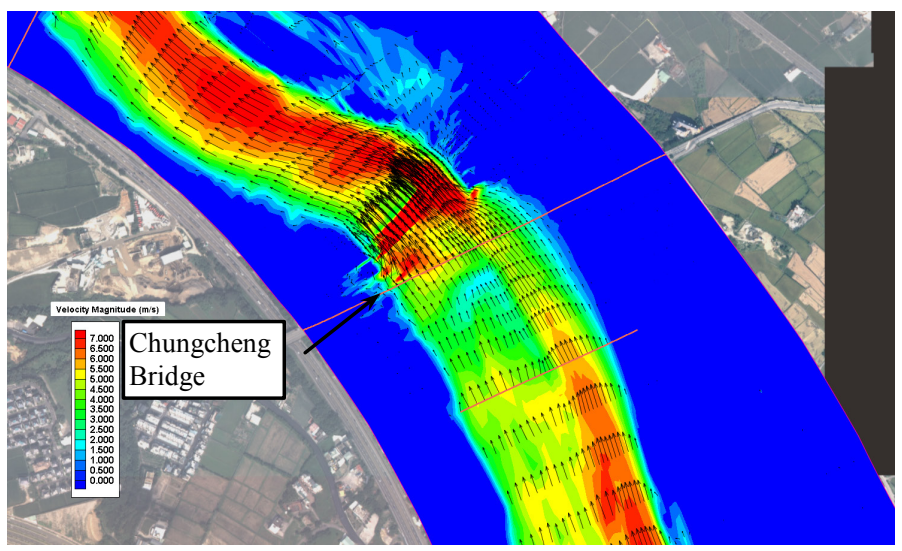

Figure 12. Simulated velocity distribution around Chungcheng Bridge when the inflow discharge is $8,190 \mathrm{~m}^{3} / \mathrm{s}\left(\mathrm{Q}_{100}\right)$.

\subsubsection{Morphodynamics}

By considering the bedrock erosion mechanism with the stream power threshold method, Figure 13 shows the simulated velocity distribution and flow field in upstream reach of Chungcheng Bridge when the peak discharge of typhoon Soudelor is $1,220 \mathrm{~m}^{3} / \mathrm{s}$. One can see that the velocity of right flow path in upstream is higher than the left one. The water does not overflow the protection work, and the maximum velocity is about $6 \mathrm{~m} / \mathrm{s}$ in the downstream channel.

Figure 14 shows the simulated and measured bed changes after the typhoon Soudelor. Since the morphological changes relate to the shear stress of flow, velocity, and bedrock erodibility index, the erosion can be estimated and predicted well with the measured data. It is noted that both flow paths have erosion, and the maximum erosion depth is about 1.5 meters. There are a few bank erosion sites near the right side flow path of the protection work.
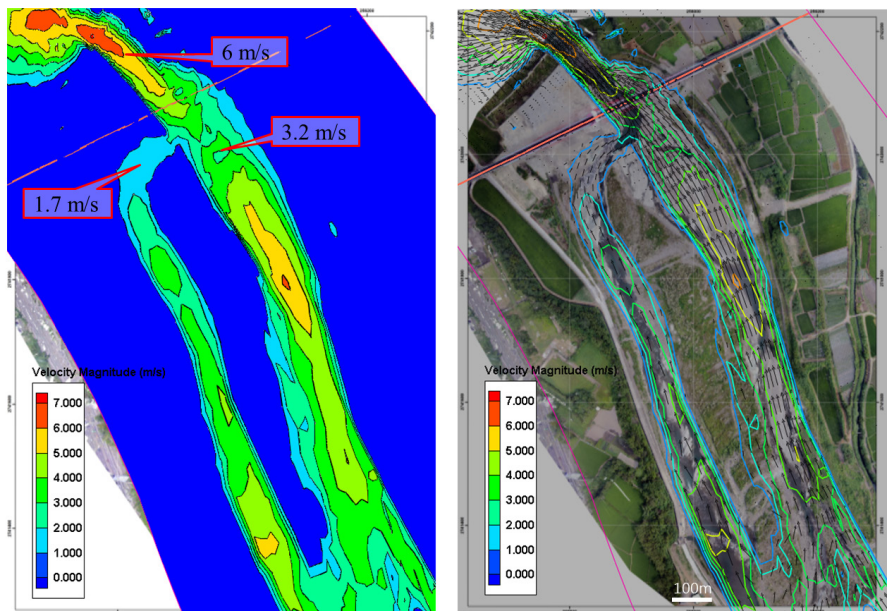

Figure 13. Simulated velocity distribution and flow field in upstream reach of Chungcheng Bridge when the peak discharge of typhoon Soudelor occurs $\left(1,220 \mathrm{~m}^{3} / \mathrm{s}\right)$.
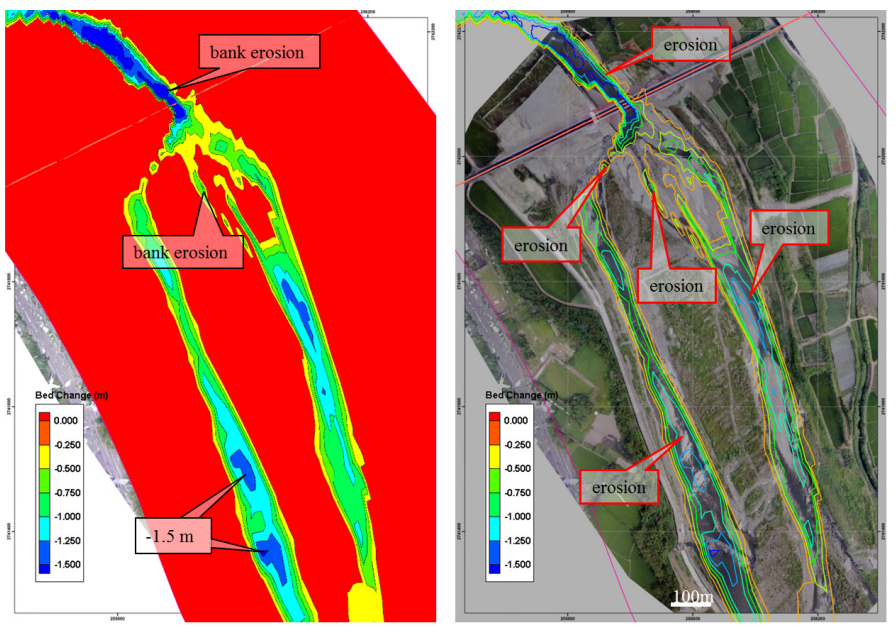

Figure 14. Simulated and measured bed changes in upstream reach of Chungcheng Bridge.

\subsubsection{Bank erosion}

To estimate the bank erosion in the nearby area of Chungcheng Bridge, a discharge hydrograph with 2year flood repeats three times is adopted (shown as Figure 15). The peak of 2-year return period discharge, $\mathrm{Q}_{2}$ is about $2,560 \mathrm{~m}^{3} / \mathrm{s}$. All the initial conditions and parameters used in the model are the same with the case of calibration.

Figure 16 shows the simulated bed change around the Chungcheng Bridge. There are erosion trends near the right bank of flow path due to the channel migration and the soft bedrock bed materials. Figure 17 shows the simulated cross-section at Chungcheng Bridge. The distance of bank erosion from the initial right bank is about 48 meters after a 2-year return period flood repeats three times. For the structural safety of the pier of Chungcheng Bridge on the floodplain, it is suggested that the protection work is necessary to modify or conduct a countermeasure for the stability of Touchien River in the future. 


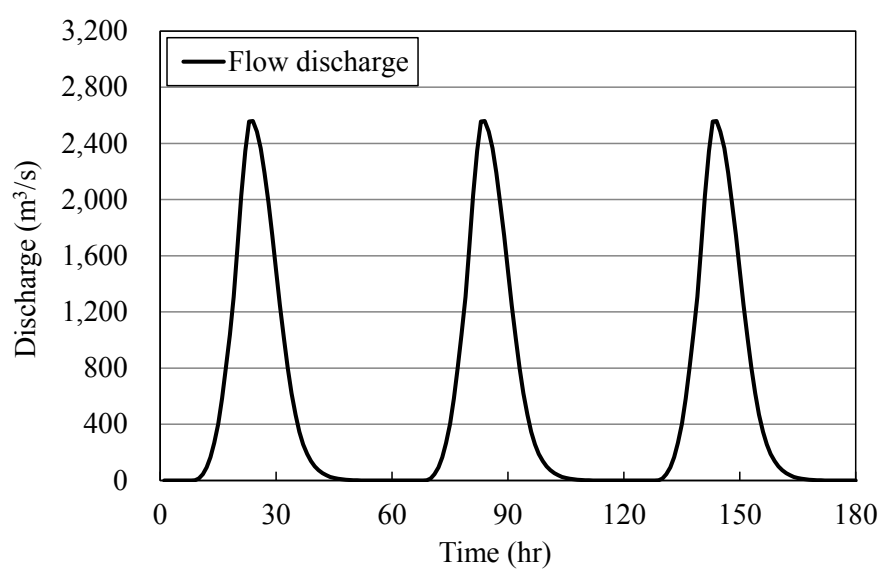

Figure 15. Inflow discharge hydrograph at Highway Bridge with 2-year flood repeats three times.

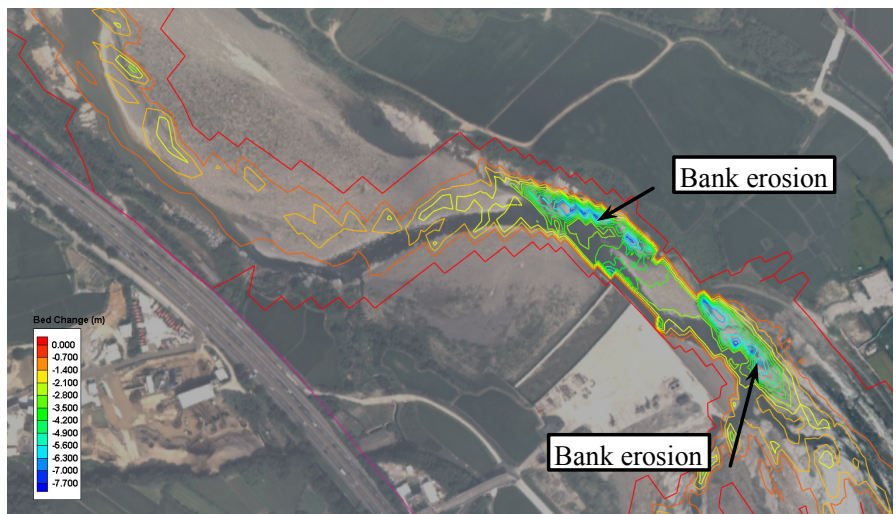

Figure 16. Simulated bed change around the Chungcheng Bridge after 2-year flood repeats three times.

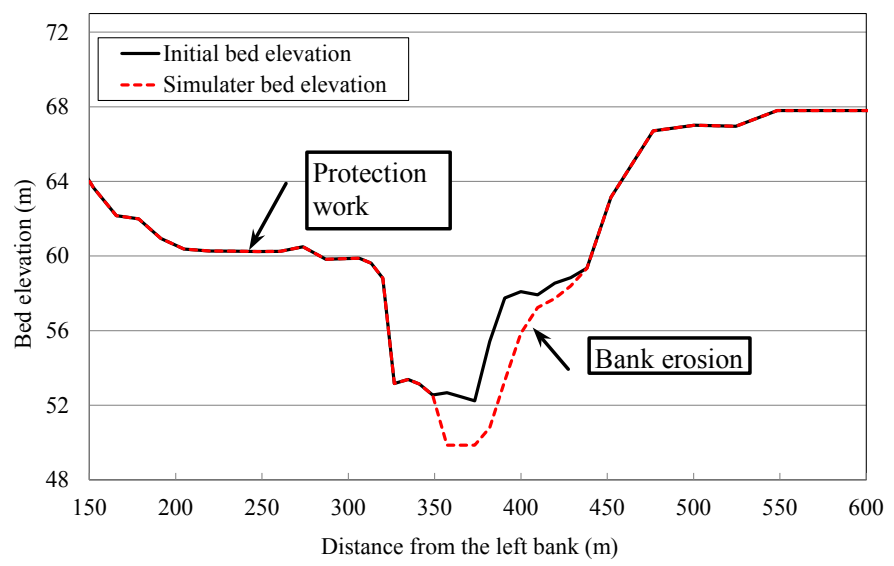

Figure 17. Simulated bank erosion at the cross-section of Chungcheng Bridge.

\section{CONCLUSIONS}

In this study, a two-dimensional mobile-bed model, called CCHE2D is adopted to simulate the bedrock erosion process around the Chungcheng Bridge. A stream power threshold with flow shear stress method of bedrock incision rate formula is established in the model. The results show that the model has the capability of simulating flow field and morphological changes in the study reach.
In lower discharge, the protection work of Chungcheng Bridge leads the flow shifting to the right bank and forms a deep main channel. By considering a discharge hydrograph with 2-year flood repeats three times, the simulated distance of bank erosion from the initial right bank is about 48 meters. For the structural safety of Chungcheng Bridge pier on the floodplain, it is suggested that the protection work is necessary to modify or conduct a countermeasure for the stability of Touchien River.

\section{REFERENCES}

Arminini, A. and Di Silvio, G. 1988. A one-dimensional model for the transport of a sediment mixture in non-equilibrium conditions. Journal of Hydraulic Research, Vol.26, No.3.

Annandale, G.W. 2006. Scour technology: mechanics and engineering practice, McGraw-Hill New York.

Huang, M.W., Pan, Y.W., Liao, J.J. 2012. A case of rapid rock riverbed incision in a coseismic uplift reach and its implications. Geomorphology, Vol 184, 98-110.

Jia, Y. and Wang, S.S.Y. 1999. Numerical model for channel flow and morphological change studies. Journal of Hydraulic Engineering, ASCE, Vol. 125, No. 9, pp. 924-933.

Jia, Y., Wang, S.Y.Y. and Xu, Y. 2002. Validation and application of a 2D model to channels with complex geometry. International Journal of Computational Engineering Science, Vol. 3, No. 1, pp. 57-71.

Jia, Y., Zhang, Y. and Wang, S.S.Y. 2008. Numerical modeling of bank erosion processes and its field application. Proceedings of the International Conference of Hydroscience and Engineering, Nagoya, Japan, September, 9-12, 2008.

Lai, T.G., Greimann, B.P., and Wu, K.W. 2011. Soft bedrock erosion modeling with a two-dimensional depth-averaged model. Journal of Hydraulic Engineering, ASCE, Vol. 137, No. 8, pp. 804-814.

Liao, C.T., Yeh, K.C. and Huang, M.W. 2014. Development and application of 2-D mobile-bed model with bedrock river evolution mechanism. Journal of Hydro-Environment Research, Vol. 8, Issue 3, 210-222.

Kirsten, H.A.D. 1982. A classification system for excavation in natural materials. The Civil Engineer in South Africa, 292308.

Sklar, L.S. and Dietrich, W.R. 2004. A mechanistic model for river incision into bedrock by saltating bed load. Water Resources Research, 40 : W06301, doi : 10.1029 / 2003WE002496.

Wu, W.M. 2001. CCHE2D Sediment transport model. Technical report No. NCCHE-TR-2001-3, National Center for Computational Hydroscience and Engineering, The University of Mississippi.

Yeh, K.C., Wang, S.Y.Y., Jia, Y., Zhang, Y., and Liao, C.T. 2008. Implement and application study of NCCHE's river migration models (II). Water Resources Planning Institute, WRA, Taiwan (in Chinese). 